\title{
Micro Array Hole Formation in Glass Using Electrochemical
}

\section{Discharge Machining}

Liang Huang ${ }^{1}$, Yan Cao ${ }^{1, *}$, Feng Jia ${ }^{1}$,Yan Lei $^{2}$

${ }^{1}$ Department of Mechanical Design, College of Mechatronic Engineering, Xi' an Technological University, Xuefu Middle Street, Wei Yang District, Xi'an City, China

2 Tool Structure Manufacturing, Xi' an KunLun Industry (Group) Company with Limited Liability, Xingfu North Street, Xin Cheng District, Xi'an City, China *E-mail: caoyan@xatu.edu.cn

doi: $10.20964 / 2019.10 .44$

Received: 5 July 2019 / Accepted: 9 August 2019 / Published: 30 August 2019

With the widespread application of non-conducting tough materials, such as glass in MEMS recent years, many difficulties have arisen in the processing of these kind of material with eigen-structure characteristics. In this paper, based on the technical advantages of electrochemical discharge machining, the mechanism of tool electrode structure and process parameters for the stability of gas film, processing efficiency and forming quality is analysed, and the machining of a glass micro-array hole is accomplished by obtaining the optimal process parameters.

Keywords: ECDM; micro array holes; gas film.

FULL TEXT

(C) 2019 The Authors. Published by ESG (www.electrochemsci.org). This article is an open access article distributed under the terms and conditions of the Creative Commons Attribution license (http://creativecommons.org/licenses/by/4.0/). 